\title{
0 compartilhamento de conhecimento em organizações apícolas: uma análise qualitativa em organizações sul-mato-grossenses
}

\author{
Victor F. Sordi Mestre em Agronegócios - Universidade Federal de Santa Catarina (UFSC) - Brasil - victor.sordi@yahoo.com.br \\ Erlaine Binotto Doutora em Agronegócios - Universidade Federal da Grande Dourados (UFGD) - Brasil - erlainebinotto@ufgd.edu.br \\ Marina K. Nakayama Doutora em Administração - Universidade Federal de Santa Catarina (UFSC) - Brasil - marina@egc.ufsc.br
}

RESUMO

Este estudo buscou caracterizar o tratamento dado pelas organizações apícolas ao compartilhamento de conhecimento entre os seus membros, no que tange às plataformas de interação de Nonaka, Toyama \& Konno (2005) e aos fatores que influenciam o compartilhamento de conhecimento de Ipe (2003). Foram entrevistados representantes de cinco organizações apícolas no estado de Mato Grosso do Sul (MS). Os resultados apontam um contexto favorável para o compartilhamento de conhecimento, entretanto, revelam que a carência de participação e interesse da maioria dos produtores para com as atividades das associações, cooperativas e federação enfraquece a disseminação, criação e perpetuação dos conhecimentos por estas organizações.

Palavras-chave: gestão do conhecimento; apicultura; mel.

\section{The knowledge sharing in the Beekeeping Organizations: a qualitative analysis in the organizations from Mato Grosso do Sul}

\begin{abstract}
This study aimed to characterize the treatment given by beekeeping organizations to sharing knowledge among its members concerning the platforms of interaction Nonaka, Toyama \& Konno (2005) and the factors that influence the knowledge sharing of Ipe (2003). Representatives of five beekeeping organizations were interviewed in the state of Mato Grosso do Sul (MS). The results indicate a favorable context for knowledge sharing, however, they suggest that the lack of participation and interest of the majority of producers regarding the activities of associations, cooperatives and federation, weakens the dissemination, creation and perpetuation of knowledge between these organizations.
\end{abstract}

Keywords: knowledge management; apiculture; honey. 


\section{INTRODUÇÃO}

Um dos elementos essenciais para a competitividade e sucesso das organizações atuais é a gestão adequada de seus conhecimentos (Karkoulian, Messarra \& McCarthy 2013; Kimble, 2013; Nonaka, Kodama, Hirose \& Kohlbacher, 2013). São esses conhecimentos que direcionam as organizações à inovação, a novas práticas de gestão, ao desenvolvimento de novos produtos, a aderência a novos mercados e a criação de vantagens competitivas (Porter, 2008; Silva \& Binotto, 2013; Wang, Su \& Yang, 2011).

Deste modo, compartilhar tais conhecimentos é de suma importância para a gestão das organizações e a falta de compreensão desse processo pode resultar em uma série de problemas, como: a ineficiência dos processos produtivos, a demora na tomada de decisões e a desintegração de equipes e departamentos (Mulder, 2012; Wang \& Noe, 2010).

$\mathrm{Na}$ apicultura não é diferente. Há conhecimentos imprescindíveis tanto na produção, como na comercialização de derivados do mel, que devem ser geridos adequadamente para a manutenção da competitividade das organizações envolvidas neste mercado (Freitas, 2004; Khan, Matos \& Lima, 2009; Wiese, 2005). Sendo assim, o sucesso na gestão desses conhecimentos depende do tratamento dado pelas organizações ao compartilhamento de conhecimento (Ipe, 2003; Wang \& Noe, 2010).

Neste sentido, este artigo propõe caracterizar o tratamento dado ao compartilhamento de conhecimentos entre os seus membros, por três associações de produtores apícolas sul-matogrossenses, uma cooperativa de apicultores e da Federação de Apicultura e Meliponicultura do Mato Grosso do Sul [FEAMS].

Para o alcance desse objetivo optou-se por uma pesquisa qualitativa com entrevistas semiestruturadas utilizando como categorias de análise os modelos teóricos de Nonaka, Toyama \& Konno (2005) e Ipe (2003).

Os resultados demonstram que os produtores pesquisados buscam compartilhar conhecimentos tácitos e explícitos, motivados pelo caráter das organizações e pelas iniciativas das entidades de apoio, porém o maior desafio encontrado pelo estudo reside na dificuldade em relação à participação de todos os membros nos eventos organizados.

Este artigo está dividido em cinco seções, esta introdução é seguida pelo referencial teórico relativo ao conhecimento e sua tipologia, as conversões de conhecimento e as plataformas de interação, além do compartilhamento de conhecimento, seguindo preferencialmente as abordagens de Nonaka et al. (2005) e Ipe (2003). Por fim, apresenta-se a metodologia utilizada, a apresentação e a discussão dos resultados alcançados e as considerações finais.

\section{REFERENCIAL TEÓRICO}

\section{O Conhecimento}

O conhecimento é considerado um fator fundamental nas organizações e é reconhecido e destacado pela literatura como fonte para a vantagem competitiva, todavia, ainda há muito para ser investigado e compreendido sobre como o conhecimento é criado, compartilhado e utilizado (Choo, 2003).

Para Davenport e Prusak (1998), o conhecimento é uma mistura de vários elementos. É fluido como também formalmente estruturado, além de intuitivo e, portanto, difícil de colocar em palavras. É desenvolvido ao longo do tempo através da experiência, que abrange aquilo que observamos em livros, cursos, palestras e também no aprendizado informal. Sveiby (2003), contudo, concebe o conhecimento como o significado das informações voltado para a ação, que capacita à ação.

Kogut e Zander (1992), Machlup (1982) e Zander e Kogut (1995), afirmam que o conhecimento é mais do que simples informações, é um conjunto de informações e know-how. Entretanto, para Bartol e Srivastava (2002), Huber (1991) e Makhija e Ganesh (1997) os termos conhecimento e informação são sinônimos, não havendo muita praticidade e utilidade de distinção entre os termos e pesquisas em compartilhamento de conhecimento.

Sendo assim, no presente estudo, o conhecimento será abordado como um conjunto de dados, informações, experiências, know-how, que após serem compreendidos, interpretados e aplicados por determinados indivíduos em determinados contextos, delimitam uma função específica, uma crença justificada (Davenport \& Prusak, 1998; Firestone \& McElroy, 2003; Marshall, 1997; Nonaka \& Takeuchi, 1997). 
Apesar de estabelecido um conceito geral para o conhecimento, Polanyi (1997), com sua afirmação de que o ser humano sabe mais do que pode efetivamente dizer, indicou que os indivíduos adquirem conhecimentos criando e organizando suas próprias experiências, em um processo interativo com a realidade. Para o entendimento deste processo é fundamental separar os conceitos de conhecimento tácito e conhecimento explícito. Ou seja, há a necessidade de se compreender melhor a tipologia do conhecimento (Nonaka \& Takeuchi, 1997).

Para Davenport e Prusak (1998), conhecimento tácito é aquele adquirido ao longo da vida, está na mente das pessoas. Sendo difícil de ser formalizado ou explicado, por sua natureza subjetiva e inerente às habilidades dos indivíduos. Já o conhecimento explícito é formal, claro, regrado, de fácil comunicação. Sendo formalizado em textos, desenhos, guardado em banco de dados e até mesmo publicado.

O conhecimento explícito, neste sentido, pode ser rapidamente transmitido aos indivíduos, formal e sistematicamente. O conhecimento tácito, por sua vez, não é de fácil visualização e é dificilmente explicável. É altamente pessoal e difícil de formalizar, dificultando a comunicação e o compartilhamento (Takeuchi \& Nonaka, 2008).

Nonaka e Takeuchi (1997) destacam que o conhecimento tácito e o conhecimento explícito apesar de serem duas classificações distintas, não são entidades totalmente separadas, e sim mutuamente complementares. Ambos interagem entre si e realizam trocas nas atividades criativas do ser humano, tais trocas são chamadas de conversões de conhecimento, que serão tratadas no tópico a seguir.

\section{A Espiral do Conhecimento}

Para Nonaka e Takeuchi (1997) existem quatro modos de conversão de conhecimento entre os formatos tácito e explícito, conforme a Figura 1. Estes modos de conversão formam uma espiral de criação do conhecimento, onde o conhecimento tácito e explícito é expandido qualitativa e quantitativamente.

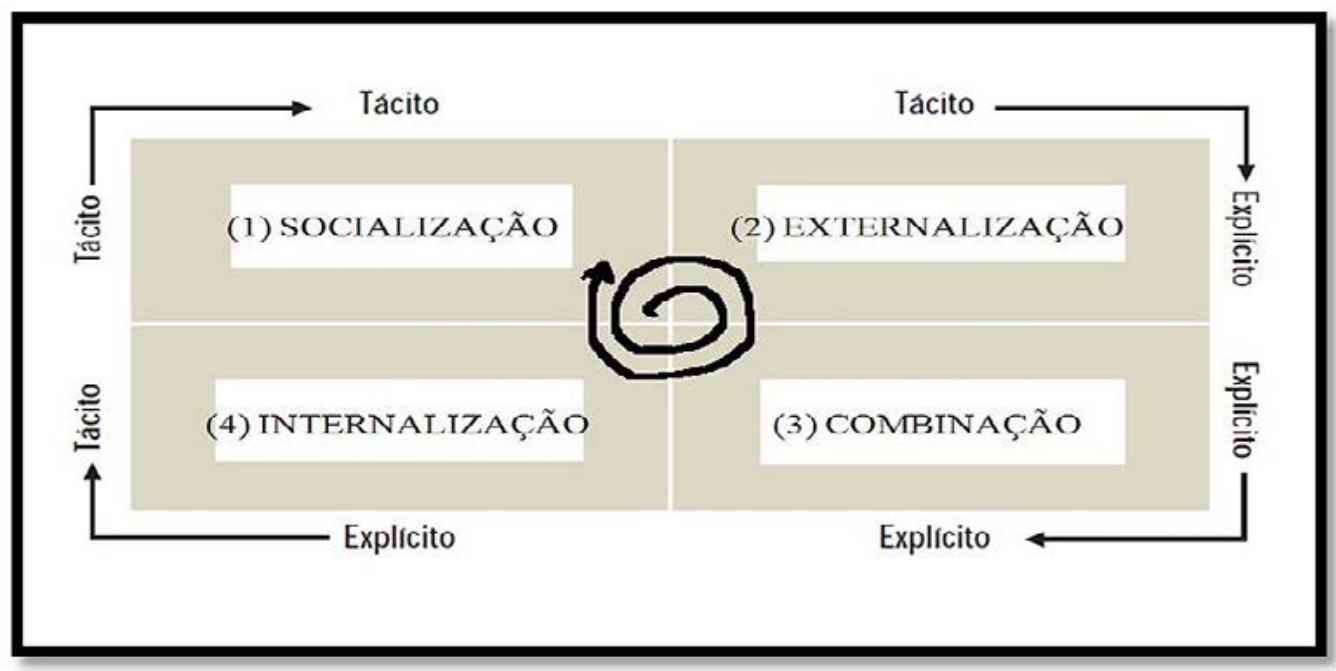

Figura 1 - Modos de conversão do conhecimento

Fonte: Adaptada de Nonaka e Takeuchi (1997, p. 68)

(1) a socialização que é a conversão de conhecimento tácito em conhecimento tácito; (2) a externalização que é a conversão de conhecimento tácito em conhecimento explícito; (3) a combinação que é a conversão de conhecimento explícito em conhecimento explícito; (4) e a internalização que é a conversão de conhecimento explícito em conhecimento tácito (Takeuchi \& Nonaka, 2008).

Para Nonaka e Takeuchi (1997) a base da socialização é a troca de experiências entre os indivíduos, o compartilhamento de conhecimento tácito, as pessoas aprendem através das experiências compartilhadas, observando, imitando, praticando, convertendo conhecimento tácito em mais conhecimento tácito. Já na externalização, o conhecimento tácito compartilhado passa a ser documentado, de maneira reproduzível, convertendo-se dessa maneira a conhecimento explícito de fácil comunicação. 
Ainda conforme Nonaka e Takeuchi (1997), na combinação o conhecimento que passou a ser reproduzível e comunicável passa a ser compilado, unido para um determinado fim, combinado em uma mídia que possa ser transmitida e multiplicada, sendo convertido, portanto, conhecimento explícito em conhecimento explícito compilado para um objetivo comum. E, por fim, na internalização os conhecimentos explícitos combinados e compartilhados são internalizados aos indivíduos, onde esse conhecimento explícito adquirido soma-se as suas experiências, aumentando, estendendo ou até mesmo reenquadrando seus próprios conhecimentos tácitos, convertendo então conhecimento explícito em conhecimento tácito.

Os quatro modos de conversão do conhecimento, que unidos formam a espiral de criação de conhecimento abordada por Nonaka e Takeuchi (1997), necessitam de uma plataforma, de um espaço de interação para acontecer. A esse espaço compartilhado de interação, Nonaka e Konno (1998) chamaram de "Ba", que pode ser conceituado, segundo os próprios autores, como um espaço compartilhado para relações emergentes que serve como base para a criação do conhecimento. Este espaço pode ser físico, virtual, mental ou qualquer combinação destes. Nonaka et al. (2005) apresentam quatro grupos de "Ba", "espaços de interação", conforme a Figura 2.

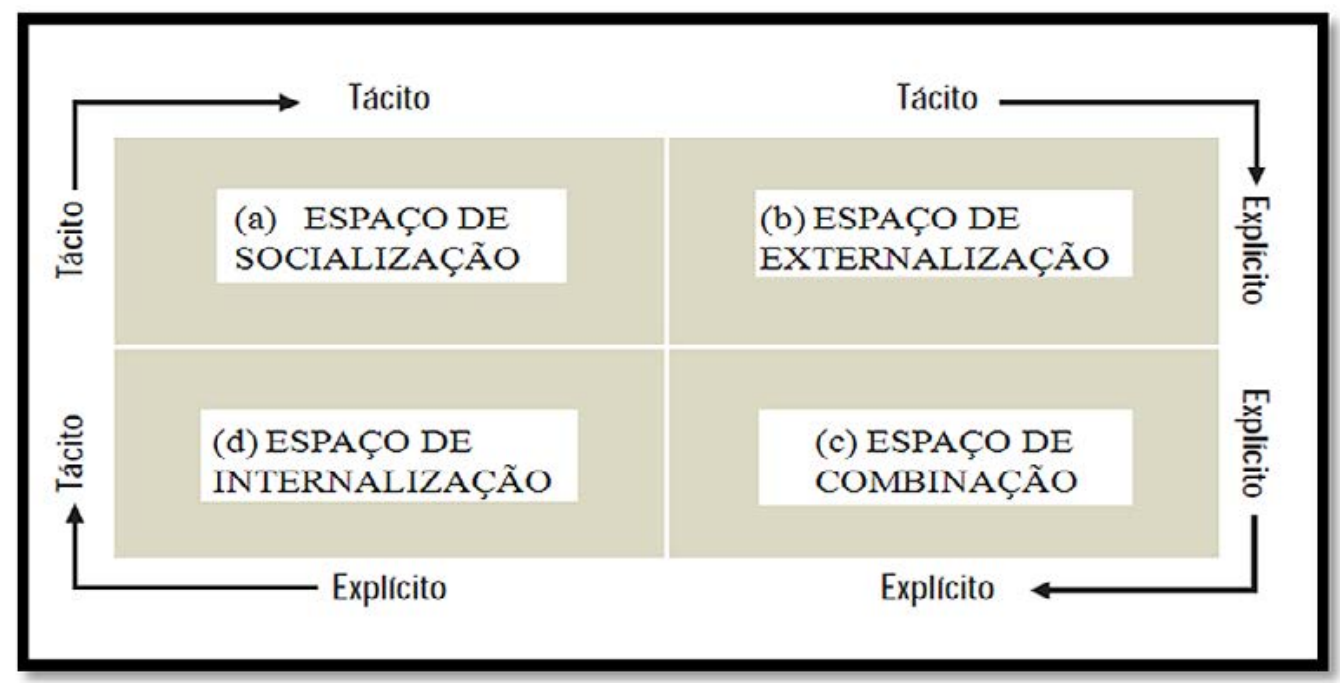

Figura 2 - Os quatro espaços de interação

Fonte: Adaptada de Nonaka et al. (2005, p.12)

a) espaços de socialização de conhecimento (originating ba), onde os indivíduos socializam o conhecimento face a face partilhando sentimentos, emoções, modelos mentais e experiências;

b) espaços de externalização de conhecimento (dialoguing ba), onde os indivíduos através do diálogo partilham suas habilidades e experiências convertendo-as em termos, conceitos, comuns aos demais indivíduos;

c) espaços de combinação de conhecimento (systematizing ba), onde é oferecido um contexto para a combinação de novos conhecimentos agora explícitos com os já partilhados pela organização ou um grupo de indivíduos;

d) espaços de internalização de conhecimento (exercising ba), onde é permitido que o conhecimento que já foi socializado, externalizado e sistematizado, seja novamente interpretado e posteriormente internalizado pelo sistema cognitivo dos indivíduos em forma de novos conceitos e práticas de trabalho que novamente serão socializadas (Nonaka et al., 2005).

Como apresentado no tópico a seguir, são nos espaços de interação entre os indivíduos que ocorre o compartilhamento de conhecimento.

\section{O Compartilhamento de Conhecimento}

Embora diversos estudos indiquem que tanto o conhecimento tácito como o conhecimento explícito possam ser compartilhados entre indivíduos e organizações, não há um consenso na literatura sobre o que é o compartilhamento de conhecimento e como ocorre esse processo (Sordi et al., 2014).

Para Bartol e Srivastava (2002) o compartilhamento de conhecimento é o compartilhamento de informações, ideias, sugestões e experiências relevantes aos indivíduos de uma determinada organização. Szulanski (2000) trata da transferência do conhecimento, ressaltando que essa 
transferência não deve ser vista como, simplesmente um ato em que um indivíduo transfere conhecimento a outro indivíduo, e sim, como um processo, constituído de diferentes estágios, cada estágio com suas dificuldades próprias.

Desta maneira, optou-se por abordar o compartilhamento de conhecimento pela visão de Ipe (2003), onde a autora concebe o ato de compartilhar conhecimento basicamente como tornar o conhecimento disponível para os outros. Entre indivíduos este processo permite uma pessoa transformar conhecimento para que seja entendido, absorvido e útil para outros atores (Ipe, 2003).

Corroboram com Ipe (2003) as concepções de Van den Hooff e Van Weenen (2004) e Brachos, Kostopoulos, Soderquist e Prastacos (2007), nas quais o processo de compartilhar conhecimento implica tanto em doá-lo como em recebê-lo, permitindo ao indivíduo combinar ideias, pontos de vista e informações previamente díspares, tornando possível construir novos conhecimentos a partir dos conhecimentos adquiridos por outros.

Sendo assim, conforme Szulanski (2000) o compartilhamento do conhecimento depende da capacidade de absorção do destinatário e da motivação que possui para buscar e aceitar conhecimentos diferentes ou novos. Neste contexto, Ipe (2003) identificou quatro fatores, em sua abordagem, que influenciam o compartilhamento de conhecimento entre os indivíduos: a natureza do conhecimento, a motivação para compartilhar, as oportunidades para compartilhar e a cultura do ambiente de trabalho voltada a compartilhar (Figura 3).

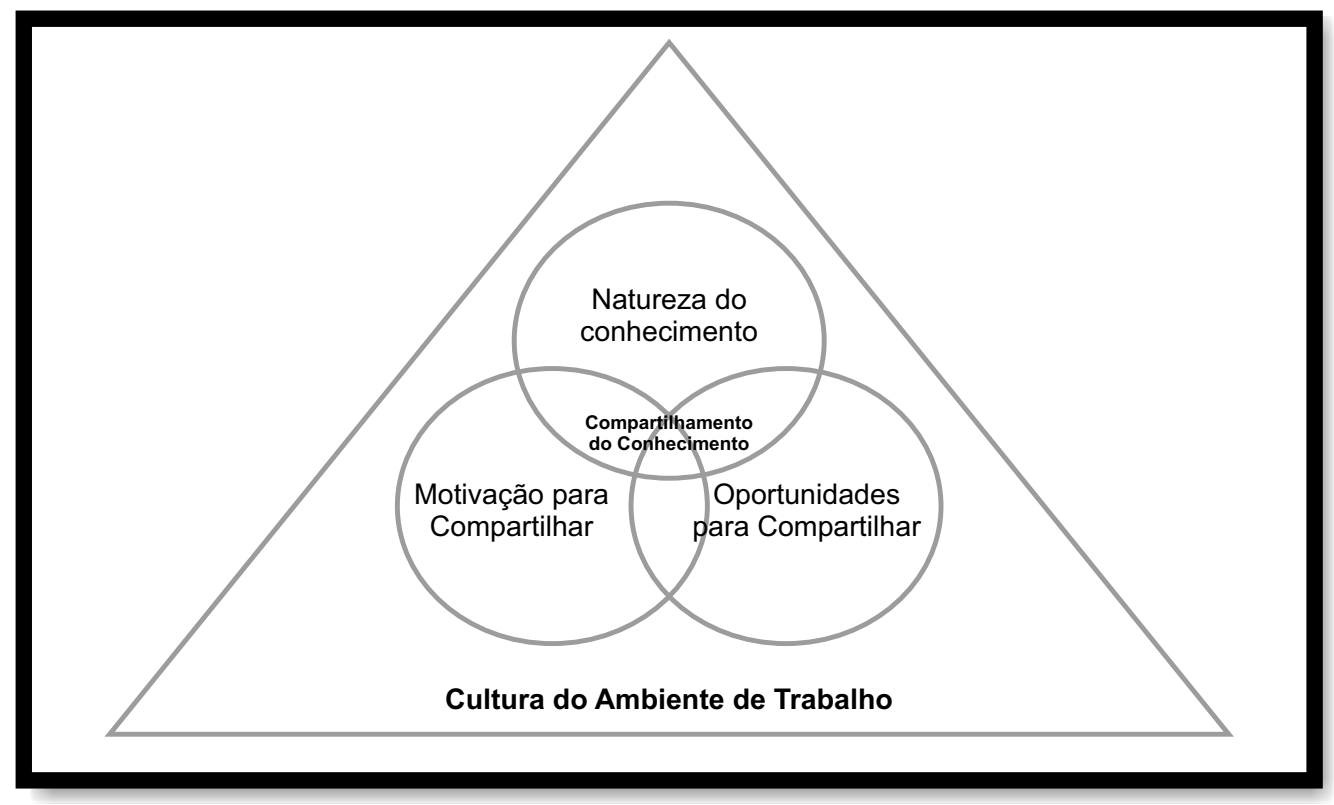

Figura 3 - Fatores que influenciam o compartilhamento de conhecimento Fonte: Adaptada de Ipe (2003)

Na figura 3, os fatores natureza do conhecimento, motivação para compartilhar e oportunidades para compartilhar se inter-relacionam dentro do contexto cultural do ambiente de trabalho. E a conjunção desses quatro fatores, conforme a abordagem de Ipe (2003), influenciam o compartilhamento de conhecimento entre os indivíduos.

A natureza do conhecimento, segundo Ipe (2003), está relacionada no sentido de o conhecimento ser tácito ou explícito e, também, no sentido de o conhecimento ter um valor comercial, esse conhecimento que tem um valor "monetário" não tem a mesma facilidade de compartilhamento.

Na visão de Stenmark (2001) a motivação para compartilhar está relacionada ao fato de os indivíduos em geral não partilharem seus conhecimentos sem saber o que podem ganhar ou perder com isso, ou seja, são necessárias motivações pessoais para os indivíduos compartilharem seus conhecimentos com os demais. A falta de motivação, conforme Szulanski (2000), poderá levar a atitudes de procrastinação, rejeição, sabotagem, passividade, não aceitação na implementação e no uso do conhecimento compartilhado.

Existem nessas relações e interações entre as partes, possíveis barreiras que podem dificultar o compartilhamento de conhecimento. Um dos principais desafios emergentes para as organizações é o de como encorajar o compartilhamento de conhecimento e eliminar tais barreiras relacionadas a esse processo (Hong et al., 2011). Essas barreiras ao compartilhamento do conhecimento podem estar relacionadas ao próprio conhecimento a ser transferido, à fonte ou ao destinatário do conhecimento, 
ou ainda ao contexto em que ocorre o compartilhamento (Barbosa et al., 2012; Tonet \& Paz, 2006).

Os indivíduos no ato de compartilhar procuram a reciprocidade, conforme Sordi et al. (2014), só compartilham se vislumbram um benefício nessa cooperação, uma contrapartida. Essa contrapartida ou troca é influenciada, conforme Ipe (2003) pelo status do receptor e do emissor do conhecimento, pela confiança entre o emissor e o receptor e pelo poder de ambos.

Na concepção de lpe (2003) as oportunidades para compartilhar, podem ser de natureza formal e informal. As oportunidades formais incluem: programas de treinamento, formação de grupos de trabalho, reuniões, sistemas baseado em tecnologia, intranet. Já dentre as informais podemos citar as confraternizações, espaços de interação social face a face e até mesmo as redes sociais.

Quanto às oportunidades para compartilhar de caráter formal, Bartol e Srivastava (2002) denominam de interações formais. Já Rulke e Zaheer (2000) de Canais de Aprendizado Intencional. Os canais de aprendizado intencional compartilham conhecimento explícito (Rulke \& Zaheer, 2000). Os canais de relacionamento, ao contrário, incluem com maior ênfase os mecanismos de compartilhamento informal, compartilhando também conhecimentos tácitos (Brown \& Duguid, 1991; Dougherty, 1992).

Para Lin et al. (2012), gerenciar os fatores individuais e organizacionais são as principais dificuldades encontradas pelas organizações em gerir o compartilhamento de conhecimento, no entanto, outra dimensão importante para o processo é a dimensão tecnológica (Yusof et al., 2012).

Os canais de aprendizado intencional por meio de redes eletrônicas e outros sistemas tecnológicos são capazes de conectar um grande número de indivíduos num curto espaço de tempo (Rulke \& Zaheer, 2000). Para Brown e Duguid (1991) e Dougherty (1992), a maior quantidade de conhecimento é compartilhada de maneira informal, por meio de canais de relacionamento e aprendizagem. Canais de relacionamento são facilitadores de comunicação face a face, a qual permite o estabelecimento da confiança, fator ressaltado como primordial para o compartilhamento, por Ipe (2003).

Quanto à cultura do ambiente de trabalho voltada ao compartilhamento de conhecimento, Ipe (2003), afirma que ela influencia os outros três fatores: natureza do conhecimento, motivação para compartilhar e oportunidades para compartilhar. Estes fatores fazem parte da cultura do ambiente de trabalho e são dirigidos pela mesma. Nesse sentido, tais fatores apresentados por Ipe (2003), conjuntamente às plataformas de interação apresentadas por Nonaka et al. (2005), serão as abordagens determinantes da análise proposta pelo presente estudo, conforme apresentado a seguir na metodologia.

\section{METODOLOGIA}

Para se alcançar o objetivo proposto utilizou-se uma metodologia com abordagem qualitativa e no que se refere aos objetivos, classificada como exploratória /descritiva (Collis \& Hussey, 2005).

Foram aplicadas entrevistas semiestruturadas com representantes de três associações de produtores apícolas sul-mato-grossenses, uma cooperativa de apicultores e da Federação de Apicultura e Meliponicultura do Mato Grosso do Sul [FEAMS]. Foram utilizados os contatos disponibilizados pela FEAMS e as organizações foram escolhidas para as entrevistas a partir da disponibilidade de seus representantes em atender a pesquisa.

Foram entrevistados os presidentes das associações: Associação dos apicultores de Caarapó (AAC), Associação Douradense de Apicultores (ADA) e da Associação Sul-mato-grossense de Apicultores (ASA). Juntamente ao presidente da Cooperbai, cooperativa de apicultores da cidade de Amambai e do consultor da Federação de Apicultura e Meliponicultura do Mato Grosso do Sul (FEAMS).

A escolha dos entrevistados foi por acessibilidade, facilidade de contato e disponibilidade para as entrevistas. As entrevistas ocorreram nas sedes das próprias organizações com transcrição simultânea das respostas. Foi utilizado como guia para as entrevistas os tópicos relacionados às categorias para análise (A1, A2, A3, A4, B1, B2, B3 e B4), que serão descritas a seguir.

Além das entrevistas foram consultados documentos disponibilizados pela FEAMS, bem como anotações e registros das organizações pesquisadas. Por se tratar de uma pesquisa exploratória, buscou-se reunir informações, identificar indícios para caracterizar o tratamento dado pelas associações, cooperativas e a própria federação ao compartilhamento de conhecimentos entre os seus membros, no que tange às plataformas de interação de Nonaka et al. (2005) e aos fatores que 
influenciam o compartilhamento de conhecimento de Ipe (2003).

Para tanto, os dados obtidos através das entrevistas foram transcritos na íntegra, posteriormente divididos e agrupados em oito categorias para análise, sendo elas, informações referentes às plataformas de interação: (A1) Espaços de socialização, (A2) Espaços de externalização, (A3) Espaços de combinação e (A4) Espaços de internalização e informações referentes aos fatores que influenciam o compartilhamento de conhecimento: (B1) Natureza do conhecimento, (B2) Motivação para compartilhar, (B3) Oportunidades para compartilhar e (B4) Cultura do ambiente de trabalho.

No próximo tópico serão analisados os resultados da presente pesquisa.

\section{APRESENTAÇÃO E DISCUSSÃO DOS RESULTADOS}

\section{Plataformas de Interação}

Com base nos resultados foi possível identificar quanto aos espaços de socialização (A1) que reuniões informais, confraternizações e outros momentos de interação face a face, ocasionados também pelos eventos formais, são recorrentes tanto nas associações, como nas cooperativas e nos eventos promovidos pela Federação. Todavia, os dados pesquisados apontam a dificuldade de se reunir os membros das diferentes organizações, visto que, em todos os casos, a falta de participação de boa parte dos membros foi um assunto constante nas entrevistas.

A entrevista feita com o representante da associação dos produtores apícolas de Caarapó revela um importante momento de socialização (A1) de conhecimentos, quando no momento da colheita e do manejo do mel, na falta de pessoal, o que é uma das características da associação, os produtores associados se ajudam mutuamente, o que contribui para o compartilhamento de experiências e cria um contexto onde a conversão de conhecimento tácito em mais conhecimento tácito é favorecida pelo "aprender" através das experiências compartilhadas (Nonaka \& Takeuchi, 1997).

Já ao se analisar a existência de eventos e ocasiões formais - que são (A2) plataformas de externalização de conhecimentos (Nonaka \& Konno, 1998) - percebe-se um número maior destes eventos (reuniões, assembleias, treinamentos, simpósios) se comparado aos eventos de caráter informal. Entretanto, a participação dos membros é ainda mais contida e de difícil trato.

Todavia, é importante destacar que para todos os entrevistados os produtores que participam destes eventos formais acrescentam muito com novas ideias e procuram resolver conjuntamente suas dificuldades. Além do fato de que - principalmente nos treinamentos técnicos disponibilizados pela FEAMS junto ao Serviço Nacional de Aprendizagem Rural [SENAR] - os produtores são capacitados com qualidade e os resultados são visíveis.

Ficou evidente que essa participação dos produtores em assembleias, reuniões para tomada de decisões, dentre outras atividades conjuntas, são imprescindíveis para a criação de um contexto onde a conversão de conhecimentos tácitos em conhecimentos explícitos seja favorecida pelos diálogos entre os indivíduos que provocam a criação de termos, conceitos, ideias comuns aos demais membros do grupo, através do compartilhamento de experiências e habilidades (Nonaka \& Konno, 1998).

Entretanto, os dados não indicam em nenhuma das organizações pesquisadas, um momento em que o conhecimento tácito compartilhado seja efetivamente documentado a fim de ser reproduzível para os demais indivíduos da organização. O conhecimento explícito foi percebido como reproduzível neste caso, somente nos treinamentos, manuais e materiais disponibilizados pela FEAMS e por parceiros, como o Serviço Brasileiro de Apoio às Micro e Pequenas Empresas [SEBRAE] e o SENAR.

São nestes momentos de interação face a face, tanto formais, quanto informais, conforme Nonaka e Konno (1998) e Nonaka e Takeuchi (1997), que ocorrem grandes ganhos quanto à criação e compartilhamento de conhecimentos. A troca de experiências, modelos mentais, a criação de vínculos sentimentais e afetivos, geram a confiança que facilita amplamente a conversão dos conhecimentos tácitos dos indivíduos para os conhecimentos explícitos que possam ser disseminados e reproduzidos.

Quanto aos espaços de combinação (A3), foi identificado através das entrevistas, um número incipiente de cursos, palestras e de interações informatizadas através de recursos eletrônicos como a internet. Tanto as cooperativas quanto as associações estudadas não possuem um espaço eletrônico específico para compartilhamento de conhecimentos, dados e informações e nem cursos, palestras ou outras ferramentas de disseminação de conhecimentos explícitos próprios. 
Foi possível identificar, através da metodologia utilizada, somente a FEAMS - junto a parcerias com o SENAR e o SEBRAE - como organização que possui iniciativas neste sentido, de combinar e disseminar conhecimentos. Dentre as quais podemos destacar: o portal eletrônico da FEAMS que possui um número razoável de informações e ferramentas para auxiliar os produtores; e os já citados cursos, palestras e treinamentos oferecidos pela federação aos apicultores.

Outro ponto importante é o fato de o perfil do produtor apícola sul-mato-grossense, embora venha mudando gradativamente nos últimos anos, ainda ser mais próximo ao de pequenos produtores rurais com poucos recursos e acesso reduzido à tecnologia e canais de informação, conforme a entrevista com o representante da federação, o que também é confirmado com os próprios membros das associações e cooperativas nos dados obtidos através das entrevistas.

São nos espaços de combinação (A3) conforme Nonaka e Konno (1998) e Nonaka e Takeuchi (1997), em que os conhecimentos explícitos reproduzíveis e comunicáveis são compilados para serem distribuídos, transmitidos, multiplicados, conhecimentos estes como as técnicas de manejo mais adequadas à realidade do produtor, o que Perez, Resende e Freitas (2004), ilustram como um fator determinante na produtividade das colméias.

Quanto aos espaços de internalização (A4), que preferencialmente, são mais espaços mentais do que físicos ou virtuais, os dados não indicam que há iniciativas no sentido de beneficiar a conversão de conhecimentos explícitos em conhecimento tácitos, se não, os cursos e treinamentos organizados pela federação em que na parte prática conjunta, os indivíduos acabam "aprendendo fazendo" o que internaliza os novos conceitos aprendidos juntamente as experiências e conhecimentos já contextualizados.

Iniciativas no sentido de proporcionar um contexto onde os produtores possam internalizar os conhecimentos explícitos aprendidos os tornando tácitos são de extrema valia para estas organizações, conforme Nonaka e Konno (1998), são nesses espaços de interação em que novos conceitos de gestão, novas práticas de produção, know-how e aplicações de conhecimentos, explícitos surgem e são evidenciadas.

Pode-se, portanto, destacar alguns pontos favoráveis e outros desfavoráveis para a criação de conhecimento e seu compartilhamento nas organizações apícolas entrevistadas, conforme a abordagem de Nonaka e Takeuchi (1997) e os dados colhidos através das entrevistas.

Há em todas as organizações tratadas espaços de socialização e externalização como reuniões, assembleias, confraternizações o que favorece as conversões de conhecimento tácito em tácito e de tácito em explícito. Todavia, não há ainda um interesse massivo dos produtores em participar tanto dos eventos formais, como dos informais. Os treinamentos, cursos, palestras e portais eletrônicos de informação são oferecidos pela federação juntamente a outros parceiros, porém em número ainda incipiente para realmente gerar efetivamente as conversões de conhecimento explícito em conhecimentos explícitos aplicados. Há a necessidade de mais espaços de internalização, já que através da metodologia utilizada não foi identificado esse contexto, onde os produtores possam aprender a fazer praticando, internalizando conhecimentos explícitos aos conhecimentos tácitos.

A seguir serão analisados, conjuntamente, os resultados acerca dos dados colhidos através das entrevistas e dos documentos disponibilizados, quanto aos fatores que influenciam o compartilhamento de conhecimentos entre os indivíduos, de acordo com a abordagem de Ipe (2003).

\section{Fatores que Influenciam o Compartilhamento de Conhecimento}

Quanto à natureza do conhecimento (B1), os conhecimentos relacionados à atividade apícola desenvolvida pelas organizações estudadas são tanto de natureza tácita, quanto explícita. Sendo que há uma quantidade incipiente de conhecimentos explícitos disponíveis aos membros das cooperativas e associações, relacionados principalmente a assuntos como: técnicas de colheita, manejo, modelos de gestão, combate a pragas, alimentação das colmeias, tanto que é um dos focos de ação de maior empenho da Federação de Apicultura e Meliponicultura do MS e de seus parceiros que visam fomentar a atividade no estado.

O conhecimento relacionado à atividade apícola também é considerado de grande valor num mercado competitivo e com necessidades de alta produtividade. Conforme Ipe (2003) isso pode influenciar em seu compartilhamento na medida em que o indivíduo queira se manter competitivo com relação aos seus concorrentes de mercado. Entretanto, nas organizações estudadas tanto nas de natureza associativa como nas de natureza cooperativa, não há indícios de que esse fator seja um limitador do compartilhamento entre os indivíduos, pelo contrário, já que há um sentimento 
de união e colaboração entre os membros o que favorece o compartilhamento, conforme Stenmark (2001).

Já quanto à motivação para compartilhar (B2), por ser uma questão mais pessoal e individualizada, com a metodologia utilizada no estudo, não foi possível obter dados significativos para a análise. Todavia, podem-se analisar as influências indicadas por Ipe (2003) que acabam favorecendo ou não a reciprocidade existente entre os indivíduos na troca de conhecimentos. Como tanto os receptores e emissores na troca de conhecimentos são produtores, teoricamente não há diferença de status e poder entre os associados e cooperados. E como ambas as organizações, associativas e cooperativas, são baseadas na confiança entre os membros, as organizações cooperativas estudadas possuem um contexto favorável para a troca de conhecimentos entre seus membros.

Para tanto, é necessário que ocorram oportunidades para se compartilhar (B3) e, conforme os dados obtidos através das entrevistas, todas as organizações pesquisadas possuem tanto oportunidades de compartilhamento de caráter informal - como confraternizações e comemorações - como também oportunidades de compartilhamento de caráter formal - programas de treinamento, assembleias, reuniões de processo decisório conjunto. Neste sentido, conforme Ipe (2003), as organizações que oferecem oportunidades de compartilhamento entre os indivíduos membros, facilitam a prospecção de conhecimentos por toda a organização. Que é o caso das organizações de produtores apícolas estudadas.

Já no que tange à cultura do ambiente de trabalho voltada ao compartilhamento, identifica-se pelos dados colhidos nas entrevistas, que os produtores associados e cooperados que realmente participam do dia a dia das organizações são minoria em relação ao total de produtores credenciados. Entretanto, entre os que participam, há uma relação de união e comprometimento em ajudar os demais produtores, o que facilita o compartilhamento de conhecimentos entre os membros.

Pode-se, portanto, destacar alguns pontos favoráveis e outros desfavoráveis no que tange aos fatores que influenciam no compartilhamento de conhecimento entre os indivíduos, nas organizações apícolas entrevistadas, conforme a abordagem de Ipe (2003) e os dados colhidos através das entrevistas.

A natureza do conhecimento a ser compartilhado entre os produtores foi deduzida como tácita e explícita, sendo que o valor dos conhecimentos pode ser considerado alto num cenário competitivo, todavia não é o caso das organizações estudas. A motivação para compartilhar em teoria é forte pelo caráter das organizações, tanto associativas como colaborativas, que baseadas na união e colaboração entre os membros criam um cenário propício ao compartilhamento de conhecimentos. As oportunidades para compartilhar são de um bom número, entretanto, o maior desafio é fazer com que todos os membros participem regularmente destes eventos. Já a cultura do ambiente de trabalho apresenta-se como favorável ao compartilhamento de conhecimentos, apesar das dificuldades de mobilização do envolvidos.

\section{CONSIDERAÇÕES FINAIS}

O objetivo do estudo foi caracterizar o tratamento dado ao compartilhamento de conhecimentos entre os seus membros nas organizações estudadas. Quanto às plataformas de interação, os resultados encontrados revelam que há espaços de socialização e externalização como reuniões, assembleias, confraternizações o que favorece as conversões de conhecimento tácito em tácito e de tácito em explicito.

No entanto, os treinamentos, cursos, palestras e portais eletrônicos de informação são oferecidos pela federação e outros parceiros, porém em número ainda incipiente para realmente gerar efetivamente as conversões de conhecimento explícito em conhecimentos explícitos aplicados. Há também a necessidade de mais espaços de internalização, onde os produtores possam aprender a fazer praticando, internalizando conhecimentos explícitos aos conhecimentos tácitos.

Em relação aos fatores que influenciam no compartilhamento de conhecimento, os resultados apontaram que os conhecimentos tácitos e explícitos a serem compartilhados entre os produtores, podem ser considerados de alto valor num cenário competitivo, todavia como se tratam de associações e cooperativas não é o caso das organizações estudadas.

Por se tratarem de organizações de natureza cooperativa, a motivação para compartilhar se demonstrou forte, baseadas, sobretudo, na união e colaboração entre os membros. Foram identificadas numerosas oportunidades de se compartilhar conhecimento, entretanto, o maior desafio é fazer com que todos os membros participem regularmente destes eventos pontuados pelos 
entrevistados. No que tange à cultura do ambiente de trabalho, os dados indicam como favorável ao compartilhamento de conhecimentos, apesar das dificuldades de mobilização do envolvidos.

Desta forma, os resultados apontaram um contexto geral favorável ao compartilhamento de conhecimentos, entretanto, também demonstraram que a carência de participação e interesse da maioria dos produtores para com as atividades das associações, cooperativas e federação, enfraquece a disseminação, criação e perpetuação dos conhecimentos por estas organizações, se caracterizando desse modo, como a principal barreira encontrada.

Tal dificuldade de mobilização desses produtores acerca do dia a dia, dos eventos e da direção de suas organizações, faz com que esse contexto considerado de maneira geral como fértil para o compartilhamento de conhecimento e o desenvolvimento da atividade, fique prejudicado, por não alcançar toda a organização, somente os que participam mais ativamente.

Desta maneira, evidencia-se que não basta que o contexto seja favorável ao compartilhamento de conhecimento, se boa parte dos indivíduos não estão envolvidos no processo. Medidas que promovam uma maior adesão dos participantes para com as organizações são essenciais para a gestão eficiente e para a manutenção da competitividade do setor. Essas medidas podem estar relacionadas à revisão das práticas adotadas para que ocorra o compartilhamento, buscando alternativas que possam viabilizar a participação dos membros, sem causar tanto prejuízo às suas atividades.

Esta pesquisa possui limites na medida em que as análises, observações e possíveis constatações não podem ser generalizadas a todas as organizações apícolas. Contudo, por se tratar de uma investigação exploratória e qualitativa de um tema novo dentro do contexto da atividade apícola, é natural que as evidências apresentadas favoreçam propostas de pesquisas futuras sobre 0 compartilhamento de conhecimento entre os agentes de organizações apícolas em outras regiões e contextos. Ressaltando-se principalmente, a necessidade da utilização de diferentes metodologias e abordagens, para o melhor aprofundamento do tema.

\section{REFERÊNCIAS}

Barbosa, José Geraldo Pereira et al. (2012). Compartilhamento de conhecimento: Um estudo de caso em uma instituição financeira. Perspectivas em Gestão \& Conhecimento, 2(1), 137-154.

Bartol, K. M., \& Srivastava, A. (2002). Encouraging knowledge sharing: The role of organizational reward systems. Journal of Leadership \& Organizational Studies, 9(1), 64-76. doi:10.1177/107179190200900105

Brachos, D., Kostopoulos, K., Soderquist, K. E., \& Prastacos, G. (2007). Knowledge effectiveness, social context and innovation. Journal of Knowledge Management, 11(5), 31-44. doi:10.1108/13673270710819780

Brown, J. S., \& Duguid, P. (1991). Organizational learning and communities of practice. Organizational Learning, 58-82. doi:10.1287/orsc.2.1.40

Choo, C. W. (2003). A organização do conhecimento: Como as organizações usam a informação para criar significado, construir conhecimento e tomar decisões. São Paulo: Senac São Paulo.

Collis, J., \& Hussey, R. (2005). Pesquisa em administração: Um guia prático para alunos de graduação e pós-graduação. Porto Alegre: Bookman.

Davenport, T. H., Prusak, L. (1998). Conhecimento empresarial. Rio de Janeiro: Elsevier Brasil.

Dougherty, D. (1992). Interpretive barriers to successful product innovation in large firms. Organization Science, 3(2), 179-202.

Federação de Apicultura e Meliponicultura do Mato Grosso do Sul. (2011). Homepage. Recuperado em 04 Abril, 2014, de http://www.feams.com.br

Firestone, J. M., \& McElroy, M. W. (2003). Key issues in the new knowledge management. London: Routledge. 
Freitas, D. G. F. (2004). Nível tecnológico e competitividade da produção de mel de abelha (Apis mellifera) no Ceará. Revista de Economia e Sociologia Rural, 42(1). doi:10.1590/S010320032004000100009

Hong, D.; Suh, E.; \& Koo, C. (2011). Developing strategies for overcoming barriers to knowledge sharing based on conversational knowledge management: A case study of a financial company. Expert Systems With Applications, 38(12), p. 14417-14427.

Huber, G. P. (1991). Organizational learning: The contributing processes and the literatures. Organization Science, 2(1), 88-115. doi:10.1287/orsc.2.1.88

Ipe, M. (2003). Knowledge sharing in organizations: A conceptual framework. Human Resource Development Review, 2(4), 337-359. doi:10.1177/1534484303257985

Karkoulian, S., Messarra, L. C., \& McCarthy, R. (2013). The intriguing art of knowledge management and its relation to learning organizations. Journal of Knowledge Management, 17(4), 511-526. doi:10.1108/JKM-03-2013-0102

Khan, A. S., Matos, V. D. D., \& Lima, P. V. P. S. (2009). Desempenho da apicultura no estado do Ceará: competitividade, nível tecnológico e fatores condicionantes. Revista de Economia e Sociologia Rural, 47(3), 651-676. doi:10.1590/S0103-20032009000300006

Kimble, C. (2013). What cost knowledge management? The example of Infosys. Global Business and Organizational Excellence, 32(3), 6-14. doi:10.1002/joe.21480

Kogut, B., \& Zander, U. (1992). Knowledge of the firm, combinative capabilities, and the replication of technology. Organization Science, 3(3), 383-397. doi:10.1287/orsc.3.3.383

Lin, N., Smith, J. A., Villarini, G., Marchok, T. P. \& Baeck, M. L. (2012). Modeling extreme rainfall, winds, and surge from Hurricane Isabel (2003). Weather and Forecasting, 25. 1342-1361. doi:10.1175/2010WAF2222349.1

Machlup, F. (1982). Knowledge: Its Creation, Distribution and Economic Significance, Volume II: The Branches of Learning. Princeton, NJ: Princeton University Press.

Makhija, M. V., \& Ganesh, U. (1997). The relationship between control and partner learning in learning-related joint ventures. Organization Science, 8 (5), 508-527.

Marshall, L. (1997). Facilitating knowledge management and knowledge sharing: New opportunities for information professionals. Online, 21 (5), 92-98.

Mulder, M. (2012). Innovative approaches for Agricultural Knowledge Management. The Journal of Agricultural Education and Extension, 18 (2), 99-102. doi:10.1787/9789264167445-en

Nonaka, I., Kodama, M., Hirose, A., \& Kohlbacher, F. (2013). Dynamic fractal organizations for promoting knowledge-based transformation: A new paradigm for organizational theory. European Management Journal, 32 (1), 137-146. doi:10.1016/j.emj.2013.02.003

Nonaka, I., \& Konno, N. (1998). The Concept of" Ba": Building a Foundation for Knowledge Creation. California Management Review, 40 (3).

Nonaka, I., \& Takeuchi, H. (1997). Criação de conhecimento na empresa. Rio de Janeiro: Elsevier Brasil.

Nonaka, l., Toyama, R., \& Konno, N. (2000). SECl, Ba and leadership: a unified model of dynamic knowledge creation. Long Range Planning, 33 (1), 5-34. doi:10.1016/S0024-6301(99)00115-6

Perez, L. H., Resende, J. D., \& Freitas, B. D. (2004). Exportações brasileiras de mel natural no período 2001-2003. Informações Econômicas, 34 (6), 28-37.

Polanyi, M. (1997). The tacit dimension. Knowledge In Organizations, 135-146.

Porter, M. E. (2008). The five competitive forces that shape strategy. Harvard Business Review, 86(1), 25-40. 
Rulke, D. L., \& Zaheer, S. (2000). Shared and unshared transactive knowledge in complex organizations: an exploratory study. Organizational Cognition: Computation And Interpretation, 83-100.

Silva, I. F., \& Binotto, E. (2013). O conhecimento e a aprendizagem organizacional no contexto de uma organização rural. Perspectivas em Gestão \& Conhecimento, 3 (1), 132-156.

Sordi, V. F., Binotto, E., \& Ruviaro, C. F. (2014). A cooperação e o compartilhamento de conhecimentos em uma cooperativa de crédito. Perspectivas em Gestão \& Conhecimento, 4 (1), 119-134.

Stenmark, D. (2001). Leveraging Tacit Organizational Knowledge. Journal of Management Information Systems, 17 (3), 9-24.

Sveiby, K. E. (2003). A nova riqueza das organizações: Gerenciando e avaliando patrimônios de conhecimento. Rio de Janeiro: Campus.

Szulanski, G. (2000). The process of knowledge transfer: A diachronic analysis of stickiness. Organizational Behavior And Human Decision Processes, 82 (1), 9-27. doi:10.1006/obhd.2000.2884

Takeuchi, H., \& Nonaka, I. (2008). Gestão do conhecimento. Porto Alegre: Bookman.

Tonet, H. C., \& Paz, M. D. G. T. D. (2006). Um modelo para o compartilhamento de conhecimento no trabalho. Revista de Administração Contemporânea, 10 (2), 75-94. doi: 10.1590/S141565552006000200005

Van den Hooff, B., \& de Leeuw van Weenen, F. (2004). Committed to share: commitment and CMC use as antecedents of knowledge sharing. Knowledge and Process Management, 11 (1), 13-24. doi:10.1002/kpm.187

Wang, D., Su, Z., \& Yang, D. (2011). Organizational culture and knowledge creation capability. Journal of Knowledge Management, 15 (3), 363-373. doi:10.1108/136732711111137385

Wang, S., \& Noe, R. A. (2010). Knowledge sharing: A review and directions for future research. Human Resource Management Review, 20 (2), 115-131. doi:10.1016/j.hrmr.2009.10.001

Wiese, H. (2005). Apicultura: Novos tempos. Porto Alegre: Agrolivros.

Zander, U., \& Kogut, B. (1995). Knowledge and the speed of the transfer and imitation of organizational capabilities: An empirical test. Organization Science, 6 (1), 76-92. doi:10.1287/ orsc.6.1.76

Yusof, Z. M. et al. (2012). Knowledge sharing in the public sector in Malaysia a proposed holistic model. Information Development, 28 (1), p. 43-54. doi:10.1177/0266666911431475 